\title{
Managing Pay for Performance: Aligning Social Science Research with Budget Predictability
}

Pauline Vaillancourt Rosenau, PhD, professor, management, policy, and community health, University of Texas Health Science Center, Houston; Lincy S. Lal, PharmD, PhD, director, Healthcare Pipeline and Research, OptumInsight; and Christiaan Lako, PhD, assistant professor, public administration, Radboud University, Nijmegen, The Netherlands

\section{EXE C U T I V E S U M M A R Y}

Managers and policymakers are seeking practical guidelines for assessing the outcomes of emerging pay-for-performance (P4P) programs. Evaluations of P4P programs published to date are mixed_-some are confusing_and methodological problems with them are common.

This article first identifies and summarizes obstacles to implementing effective $\mathrm{P} 4 \mathrm{P}$ programs. Second, it describes results from social science research going back several decades to support evidence-based P4P best practices. Among the findings from this research, the zero-sum and "earn it back" P4P incentive systems have important drawbacks and may be counterproductive, neither reducing health system costs nor improving quality. The research suggests that punishing participants for low performance may further reduce individuals' performance, especially when involvement is required. We suggest that optimal P4P systems are those that reward all participants for performance improvements. Third, the article links P4P design to budgetary considerations. $\mathrm{P} 4 \mathrm{P}$ program designs that provide incentives while improving quality and reducing costs are critical if budget neutrality is a priority for the organization and its resources are limited. In these types of P4P designs, cost calculations are straightforward: The greater the participation, the higher the savings. The article concludes by recommending an evidence-based P4P approach for practitioners that can be implemented without large upfront investment. More research on this topic is also advised.

For more information about the concepts in this article, please contact Dr. Rosenau at Pauline.Rosenau@uth.tmc.edu. 


\section{INTRODUCTION}

The variety of pay-for-performance ( $\mathrm{P} 4 \mathrm{P})$ programs is vast, and practitioners need guidance in determining which types are most successful and where to begin implementing one (Young 2007). According to the Agency for Healthcare Research and Quality (2006), P4P payment systems are designed to "offer financial incentives to physicians and other health care providers to meet defined quality, efficiency, or other targets." The collective goal of the P4P approaches is to reduce health system costs while improving quality.

$\mathrm{P} 4 \mathrm{P}$ incentive systems are having an enormous impact on healthcare delivery in the United States (Epstein 2007). P4P is among the most important developments in the US healthcare sector since managed care and capitation (Kellis and Rumberger 2010). It aims to change the behavior of physicians, patients, and those working in hospitals through a system of rewards and punishments. A P4P reward or bonus for physicians might take the form of a salary add-on to the general fee-for-service. A reward for hospitals might be payments beyond those received through the diagnosis-related group-based scheme. A punishment under the P4P system might mean reduced compensation or some other penalty.

The purpose of this article is to assess and prioritize $\mathrm{P} 4 \mathrm{P}$ programs for practitioners. First, we summarize the main obstacles to achieving a successful $\mathrm{P} 4 \mathrm{P}$ program. Second, we employ theoretical principles and research findings from behavioral science and business to demonstrate how to improve P4P results. Third, we show the link between
P4P systems and budget predictability. Finally, we recommend to practitioners a viable $\mathrm{P} 4 \mathrm{P}$ design that includes evidence-based best practices and does not require a large initial investment.

\section{ISSUES SURROUNDING PAY-FOR-PERFORMANCE I M PLEMENTATION}

\section{Results Are Mixed}

Taken together, the results of P4P programs in the United States can be characterized at best as mixed and at worst as inconclusive (Peterson et al. 2006; Wodchis, Ross, and Detsky 2007). Some studies outline clear evidence of P4P effectiveness (Abelson 2007; CMS 2008). Others indicate that P4P innovations fail or the results are inconclusive (Glickman et al. 2007; Pearson et al. 2008; Damberg et al. 2009). In short, "pay-for-performance may not, necessarily, have the dramatic and or even predictable effects touted by its enthusiasts" (Mullen, Frank, and Rosenthal 2010). Mixed results have also been reported in other countries (Campbell et al. 2007, 2009; McDonald and Roland 2009).

\section{Methodological Problems Abound}

Several reasons explain why results from $\mathrm{P} 4 \mathrm{P}$ experiments vary widely, and some of these are related to methodological problems. The samples involved are often very small. Participation in these programs is seldom based on random samples of practitioners or hospitals-it usually involves voluntary participation, leading to selection bias. Changes in performance measured under these $\mathrm{P} 4 \mathrm{P}$ programs sometimes coincided with structural changes or operational 
reorganization such that any observed change may not be attributable to P4P alone (Golden 2006; Pink et al. 2006). Positive results were sometimes attributable to "secular trends," whereby researchers mistakenly concluded that P4P improves quality or cost when, in fact, most organizations operating in the healthcare sector were improving, even those in which P4P was not present.

According to some policy experts, $\mathrm{P} 4 \mathrm{P}$ is observed to have failed, in part, because incentives are not large enough to change behavior. For example, P4P in the United States has not proved as effective as in Britain, where rewards are far greater-in some cases up to 50 percent of a physician's salary (Davis 2008; Doran, Fullwood, and Gravelle 2006) - than those in US P4P programs, which are seldom more than 5 percent of a physician's salary (Advisory Board Company and Foundation 2008). But even in Britain, generous rewards have been found insufficient to improve quality in some cases (Serumaga et al. 2011).

\section{Obstacles Emerge}

Common obstacles to the successful use of $\mathrm{P} 4 \mathrm{P}$ programs have been identified and are related to both performance and process variables (McDonald and Roland 2009; Hoff et al. 2011). All reimbursement systems encourage manipulation of one sort or another, and P4P is no exception (Galvin et al. 2005; Hamblin 2008; Hayward and Kent 2008). The Journal of the American Medical Association has even published a guide explaining how providers can "game" a P4P system (Hayward and Kent 2008). Other troubling aspects include the fact that under P4P incentive systems providers tend to treat a presenting patient even if the diagnosis is unclear or uncertain (Jauhar 2008) and that when P4P incentives are in place, continuity of care may be reduced (Campbell et al. 2007, 2009). Furthermore, P4P increases the difficulty in treating patients with multiple medical problems (Young et al. 2010). These issues arise primarily because P4P focuses a provider's attention on the reward, and this diversion may result in oversights in addressing the totality of a patient's healthcare needs (Campbell et al. 2009).

$\mathrm{P} 4 \mathrm{P}$ has been found to increase health disparities among populations in several ways. Most importantly, research suggests that physicians in these programs avoid sicker patients because they perceive those patients as likely to lower their quality scores. Because many members of minority groups have poor health, they tend to fall into the category of patients to be avoided by P4P-participating physicians (Blustein et al. 2011; Casalino et al. 2007b). In addition, many physicians view P4P as intrusive, controlling, and punitive rather than as educational (Giraud-Roufast and Chabot 2008). Among those physicians who do support it, many have little concrete experience with $\mathrm{P} 4 \mathrm{P}$ programs (Casalino et al. 2007a).

Another problem for P4P programs involves how to bring them to an end if they are not needed anymore or if funding is no longer available. One classic sociological study found that when workers are being observed, they respond in socially desirable ways; the phenomenon is known as the Hawthorne effect (Mayo 1933). Indeed, tests of the Hawthorne effect in the health 
sector find that intensive follow-up of participants in a clinical trial results in better outcomes than does minimal follow-up (McCarney et al. 2007). This finding suggests that caution should be exercised in the decision to allow $\mathrm{P} 4 \mathrm{P}$ programs to lapse. One study reports that when providers ceased to be rewarded for their new behavior, they reverted to the old behavior (Lester et al. 2010). Another study found that P4P programs that initially demonstrated improved performance tended to taper off in the fourth and fifth years (Werner et al. 2011).

\section{APPLYING BEHAVIORAL AND SOCIAL SCIENCE TO PAY FOR PERFORMANCE}

Research results from behavioral science regarding individual behavior and system-level characteristics are not always explicitly incorporated into P4P systems (Mehrotra, Sorbero, and Damberg 2010). Too often P4P design is grounded in intuition and untested assumptions (Meltzer 2009). Here we present social science and behavioral science findings and point to their practical implications for P4P design. (See Exhibit 1.) Of course, such applications are no guarantee of success, no matter how logical and rational, because they have yet to be tested.

Social science research suggests that incentives should be both linked to a specific time frame and proximate to the desired behavior. The opportune moment to reward an individual for a specific behavior is immediately after that behavior is elicited ( $\mathrm{O}^{\prime} \mathrm{Daly}$ and Fantino 2003). Furthermore, "People place more weight on the present than the future-they're more attracted by immediate than delayed benefits" (Volpp et al. 2011). Therefore, if the time span between the receipt of the reward or penalty and the financial effects on the individual or organization are large, as is usually the case with $\mathrm{P} 4 \mathrm{P}$ programs, the impact is reduced (Volpp et al. 2011).

$\mathrm{P} 4 \mathrm{P}$ programs should target for reward those individuals or entities whose behavior you wish to change, such as a group, an individual physician, a hospital, or a patient. However, $\mathrm{P} 4 \mathrm{P}$ programs typically are not structured to do so. For example, they reward a physician if his or her patients reduce tobacco use, lower cholesterol levels, comply with orders to take medication, or lose weight. In these cases the incentive is "distant" rather than proximate to the behavioral change. Rewarding those who successfully change their lifestyle and medication compliance is more in agreement with behavioral research (Volpp et al. 2009; Wharam and Sulmasy 2009). In fact, because even small financial incentives change patient behavior, rewarding the patients rather than the physicians may be effective (Oliver and Brown 2011).

The most successful incentive structures match an individual's values and goals. Equally important to success is that $\mathrm{P} 4 \mathrm{P}$ programs be aligned with an individual's personality (Hamblin 2008). A provider that is motivated by self-interest might be open to P4P formats that are less than altruistic in their approach. Research suggests that in the general population about 50 percent of the population is altruistic, one-third is self-interested, and the rest exhibit a mix of these characteristics (Camerer 

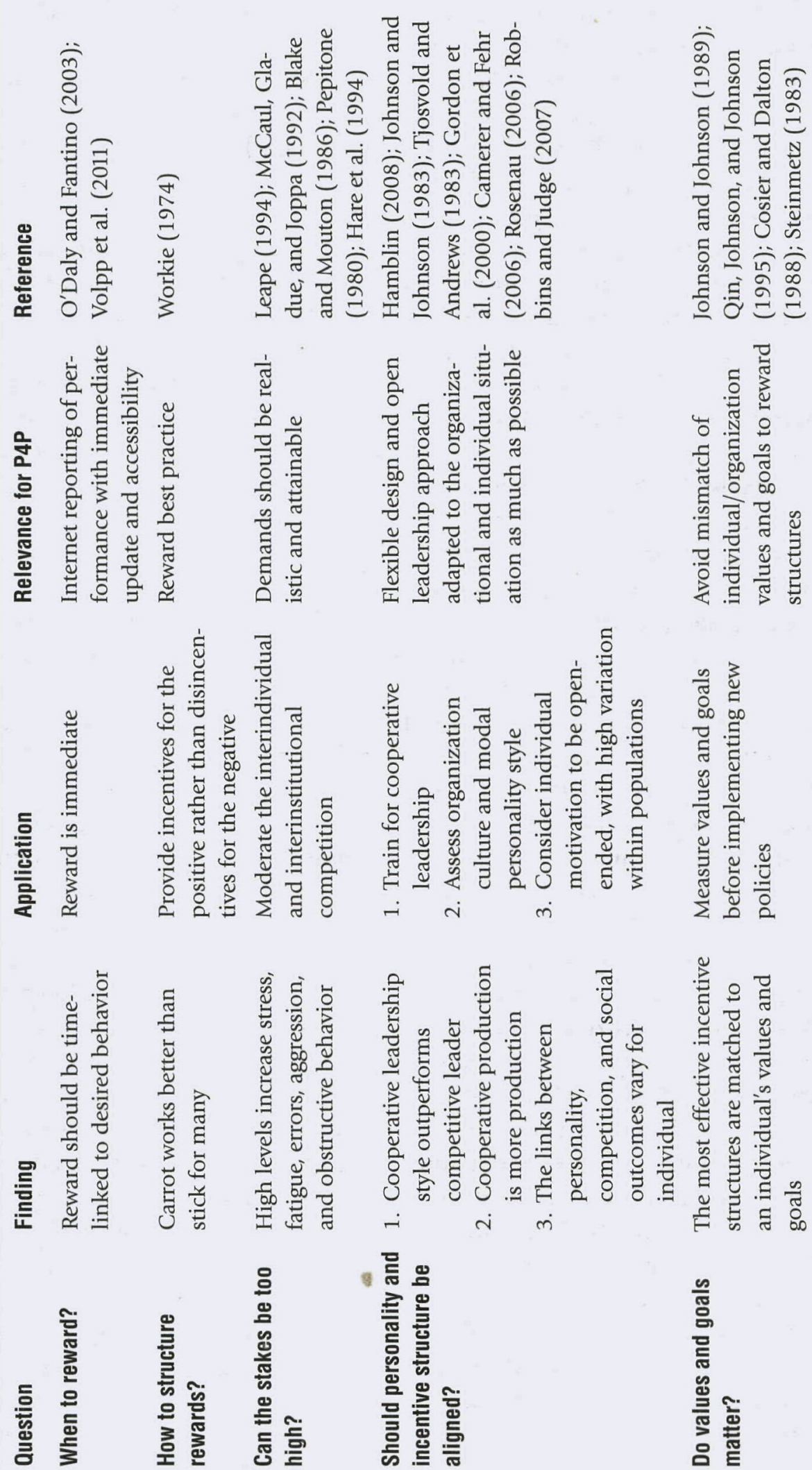
and Fehr 2006; Rosenau 2006). Some personality types respond to one form of reward to a greater degree than to others. For example, in the health sector some physicians are likely to respond to $\mathrm{P} 4 \mathrm{P}$ programs that are linked to the ethic of providing healthcare to the whole population rather than to personal financial incentives (Christianson, Leatherman, and Sutherland 2008).

Social science research points to the possibility that nonfinancial P4P rewards are often overlooked, though they may be highly effective for many individuals. For those attracted to their field because of the intrinsic value they derive from it, nonmonetary rewards could be optimal because such rewards fit their values (Strack and Deutsch 2004; Randolph 2005). In line with this expectation, a recent study found that a number of doctors left a hospital after a P4P program was implemented whose incentives were financially based (Golden and Sloan 2008). P4P is also said to crowd out individual initiative and discourage efforts to improve quality in situations where monetary gain is seen as substituting for professional and personal pride in performance. In some cases, emphasizing monetary $\mathrm{P} 4 \mathrm{P}$ incentive systems may even be counterproductive (Ryan and Deci 2000). Increased pay has been reported to reduce physicians' commitment to their hospital (Dukerich, Golden, and Shortell 2002; Wynia 2009), though this effect is not always observed (Young et al. 2010). In short, once a minimum level of extrinsic reward (financial) is reached, intrinsic rewards (values) may become the primary motivation factor (Pfeffer et al. 1998).
Other examples of effective nonmonetary incentives or motivators involve public recognition, participation, praise, and an understanding that they (individuals or institutions) are "doing good" (Robbins and Judge 2007). The opportunity for more challenging work is an additional nonfinancial motivator (Dukerich, Golden, and Shortell 2002; Golden 2006). Motivation may differ from individual to individual (Steinmetz 1983). However, applying different $\mathrm{P} 4 \mathrm{P}$ formats to various individuals in an organization may be difficult to implement in the real world.

For decades social scientists have studied how best to motivate the individual in the workplace. Several theories of motivation from different disciplines are relevant to $\mathrm{P} 4 \mathrm{P}$ design, among them the field theory (Lewin 1943), goal theory (Locke and Latham 1990), expectancy theory (Vroom 1964), and hierarchy of needs theory (Maslow 1943). Not all are evidence based. Some have been modified to improve their ability to structure motivation, and these are the most useful for P4P design. Alderfer's (1969) work on Maslow's hierarchy of needs theory is an example. In the end, P4P design implicitly asks the question, "Are incentives best structured as rewards or as punishments, or both?" Almost forgotten are the studies indicating that, on balance, a positive reward is as effective as or more effective than a negative incentive (Workie 1974). Positive motivation, including increased workplace opportunities, is more effective than instilling fear or making threats (Steinmetz 1983). Experiments in the field of education confirm this 
finding (Johnson and Johnson 1983). Another study that can be applied to P4P programs reports that for many individuals, workplace practices that require interindividual cooperation are associated with higher productivity than those employing competition between individuals in the organization (Cosier and Dalton 1988; Lam et al. 2011).

P4P designs should incorporate findings from research on the effects of various forms of competition, on transparency, and on innovation. Competition internal to an organization is detrimental to attaining organizational goals, and it reduces individual and group performance (Rosenau 2003, Chapter 3). An absence of P4P contractual transparency can increase competition internal to a program, which indirectly reduces productivity (Thompson et al. 2002). Restrictive P4P confidentiality contracts may reduce collaboration and efficacy. Finally, some evidence suggests that excessive competition in P4P programs could discourage innovation (Jauhar 2008).

Social science research predicts that zero-sum P4P designs that reward some individuals or groups at the expense of others have the potential to disrupt organizational performance and reduce overall individual and organizational achievement. Those forms of P4P involving zero-sum competition take money from participants who do not meet P4P reward criteria and give it to those who do meet the criteria (Exhibit 2). This type of competition polarizes an organization and divides the individuals who work there into winners and losers (Kelly 2010). Those at the low-performing end of the continuum may become discouraged, reduce their effort, and even give up trying to reach the level of performance required to merit a reward (Himmelberg, Hubbard, and Palia 1999; Vaughan 1999). If social science research is accurate, these $\mathrm{P} 4 \mathrm{P}$ designs are likely to increase stress, fatigue, aggression, and obstructive behavior (Hare et al. 1994; Stanne, Johnson, and Johnson 1999). In addition, they may reduce the self-esteem of some workers (Meyer 1975), lower safety performance, and reduce workplace morale (FitzRoy, Acs, and Gerlowski 1998).

Does this form of P4P lead to competition that subsequently reduces performance for those receiving a penalty? Research indicates that this problem may not arise in $\mathrm{P} 4 \mathrm{P}$ programs where participation is voluntary (Chen et al. 2010). Conversely, decades of behavioral research across many sectors suggests the opposite is likely to be true where participation is not voluntary.

A similar form of $\mathrm{P} 4 \mathrm{P}$ reduces the base compensation for all individuals, or base reimbursement for the organization, with an explicit "earn it back" strategy. Only those who meet the P4P standard will receive the same pay as before the program was initiated. The effects discussed earlier resulting from zero-sum P4P may apply to this P4P design as well.

$\mathrm{P} 4 \mathrm{P}$ designs that take from the lowest performers to reward the highest performers and those that reduce the base and require that individuals earn back any compensation lost to the program have one important advantage over others that makes them extremely attractive to managers: They are budget neutral and thus permit budget predictability. 
The amount needed to finance these forms of P4P can be anticipated in advance and entered into the organization's annual budget with known fiscal consequences. This advantage holds for all forms of $\mathrm{P} 4 \mathrm{P}$ in which the amount of the reward comes from the penalty payments assessed to those who do not perform up to expectations. Yet better methods are available to achieve the goal of budget neutrality without employing a zero-sum $\mathrm{P} 4 \mathrm{P}$ that has substantial negative externalities.

\section{THE IDEAL P4P}

Social science research supports $\mathrm{P} 4 \mathrm{P}$ program designs that set a standard for excellence and offer a reward for all who attain this level of performance. In such a design, all who meet the standard are rewarded, and none are punished for not meeting the standard. This P4P strategy reduces the level of stress and anxiety associated with zero-sum incentive systems. The downside is that it is difficult to budget for because one never knows in advance how many individuals will perform to the standard required to be rewarded. Resources are limited, and provider/ player uptake, or involvement, is hard to predict. If uptake is great, huge budget overruns may result, raising a dilemma: How can a P4P program be structured to avoid the downside of zero-sum systems and yet result in limited budgetary consequences?

\section{Budgeting for Optimal P4P Systems}

Achieving budget neutrality or budget predictability is vital for $\mathrm{P} 4 \mathrm{P}$ programs. Some of the largest and most wellknown P4P programs in the United
States are optimal in that they are budget neutral, but they may not be ideal because they have the externalities outlined earlier. For example, as indicated in Exhibit 2, zero-sum P4P strategies are employed by Medicare and the Veterans Health Administration. Typically these programs offer 10 percent bonuses to the top 10 percent of performers and impose a financial penalty of 10 percent reductions in pay to the bottom 10 percent of performers (Burton 2011). By definition these approaches are budget neutral.

Some P4P structures can be optimal in the larger sense in that existing social research supports them and they are also budget neural. They create an alignment between provider behavior change and the organizations' need for budget predictability or budget neutrality. These P4P programs place success and rewards within reach of all participants and at the same time achieve the desired performance criteria that result in a cost savings to the system as a whole. This relationship is outlined in Exhibit 3. The greater the uptake, the larger are the realized savings. In other words, the more "winners" that result from this type of P4P, the more savings accrue to the organization. "The more you buy, the more you save" may not be possible to fulfill in every situation, but where it is, this form of $\mathrm{P} 4 \mathrm{P}$ is optimal.

A real-world example is that of a P4P program offered by Highmark, a Pennsylvania-based health insurance plan, that targeted physician prescribing behavior for improvement. Primary care physicians were rewarded a bonus of $\$ 3.00$ to $\$ 9.00$ for every fee-forservice patient for which they wrote a 


\section{EXHIBIT 2}

\section{P4P Systems That Are Budget Neutral but Not Optimal}

Take from the lowest performer to give to the top performer classic zero-sum competition

\section{Reduce the base} compensation and use the saved revenue to finance bonuses to top performers.
- Example: Medicare's experiments-top 10\% receive a bonus while bottom $10 \%$ receive a financial penalty.

- Behavioral science research suggests that those at the bottom "give up."

- Compensation reduction with an "earn it back" approach has not been demonstrated to improve organizational morale.

- Research suggests that timing of reward makes for broad discontent.

- "Time-link" principle is violated.

\section{EXHIBIT 3}

\section{Solutions to P4P Problems}
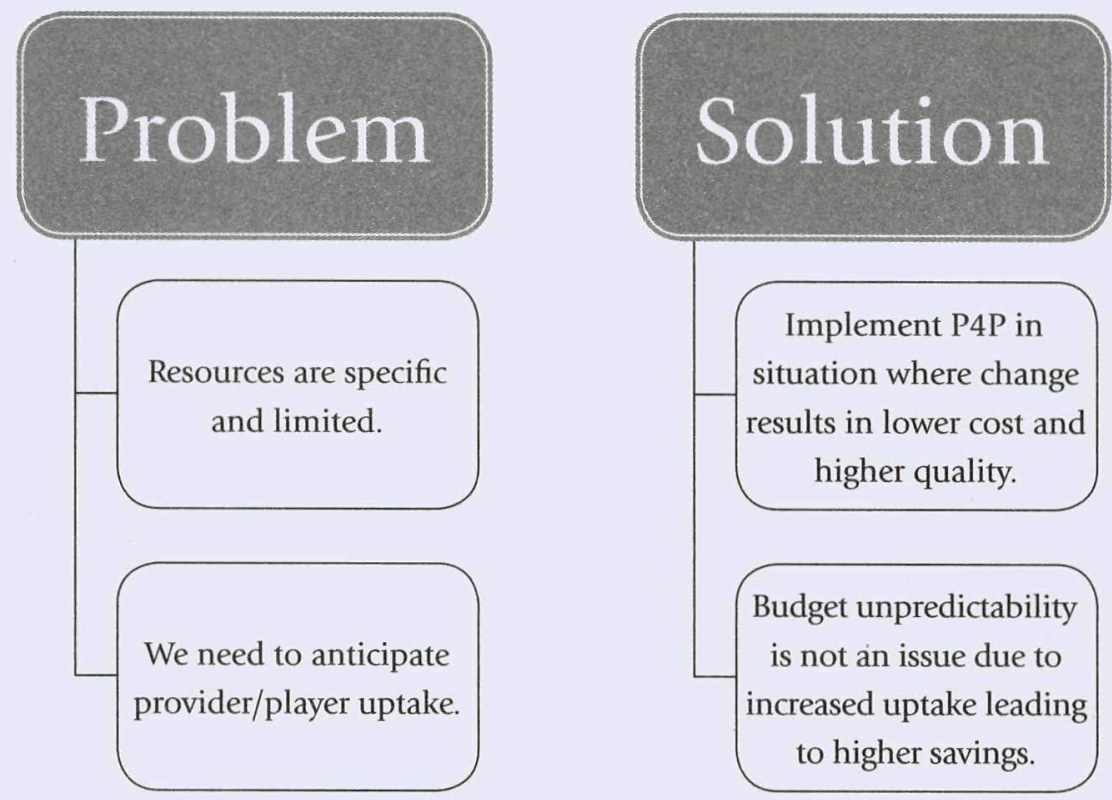
prescription for a generic rather than a brand name medication. While many such private $\mathrm{P} 4 \mathrm{P}$ incentive systems are considered proprietary, Highmark has publicized and shared its program design, structure, and outcomes performance results. With 5,000 physicians participating, the prescribing of generics increased from 46 percent to 73 percent in four years. Savings to Highmark amounted to $\$ 87$ million in 2010 alone (Diamond 2010).

Managers and their organizations must be able to anticipate how much a P4P program will cost. In general, obtaining an accurate assessment of return on investment for a $\mathrm{P} 4 \mathrm{P}$ program is complicated and expensive-in many cases it cannot be calculated with precision in advance of the program's implementation (Curtin et al. 2006). This consideration strengthens the appeal of the optimal $\mathrm{P} 4 \mathrm{P}$ programs described in this article.

\section{CONCLUSION}

$\mathrm{P} 4 \mathrm{P}$ is a blunt instrument whose implementation is made more complicated by the unexpected consequences outlined here. P4P has advantages as well as disadvantages, and they need to be consciously and fairly assessed by managers and policymakers. No P4P program can guarantee success, but if the accumulated evidence of behavioral research is applied to their design, optimal P4P systems should permit all participants to be rewarded for quality improvements that also reduce costs (Exhibit 4). From this research we have determined that if carefully chosen and structured appropriately, the cost of pay-for-performance programs can be recovered at the same time that unexpected and expensive externalities can be avoided. Further investigation and research should be a priority to determine if this approach is as effective as we expect in the real world of healthcare environments.

\section{EXHIBIT 4}

\section{Putting Knowledge into Practice}

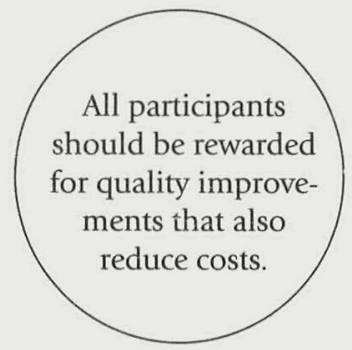

Focus only on programs where savings from cost reductions will compensate for the cost of the program.
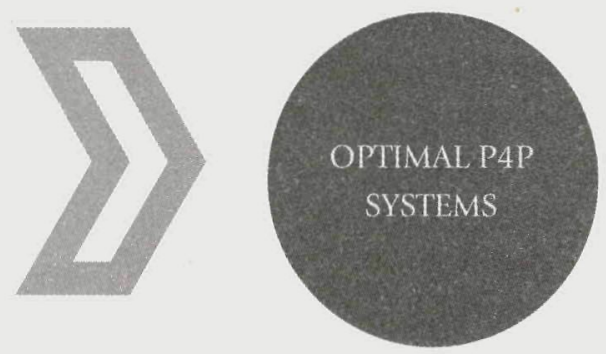

All P4P incentive programs are not equal. 


\section{REFERENCES}

Abelson, R. 2007. "Bonus Pay by Medicare Lifts Quality." The New York Times, January 25.

Advisory Board Company and Foundation. 2008. Experts Testifying Before Senate Panel Extol Incentives, Standardization as Means to Improve Quality of Care. Medical News Today, September.

Agency for Healthcare Research and Quality (AHRQ). 2006. Pay for Performance (P4P): AHRQ Resources. AHRQ. Published in March. www.ahrq.gov/qual/ pay4per.htm.

Alderfer, C. P. 1969. "An Empirical Test of a New Theory of Human Needs." Organizational Behavior and Human Performance 4: 142-75.

Blake, R. R., and J. S. Mouton. 1986. "From Theory to Practice in Intergroup Problem Solving." In S. Worchel and W. G. Austin (Eds.), Psychology of Intergroup Relations. Chicago: Nelson-Hall.

Blustein, J., J. S. Weissman, A. M. Ryan, T. Doran, and R. Hasnain-Wynia. 2011. "Analysis Raises Questions on Whether Pay-forPerformance in Medicaid Can Efficiently Reduce Racial and Ethnic Disparities." Health Affairs (Millwood) 30 (6): 1165-75.

Burton, T. M. 2011. "Data Spur Changes in VA Care." Wall Street Journal, March 29, D4.

Camerer, C., and E. Fehr. 2006. "When Does 'Economic Man' Dominate Social Behavior?" Science 311: 47-52.

Campbell, S., D. Reeves, E. Kontopantelis, E. Middleton, B. Sibbald, and M. Roland. 2007. "Quality of Primary Care in England with the Introduction of Pay-for-Performance." New England Journal of Medicine 357 (2): 181-90.

Campbell, S., D. Reeves, E. Kontopantelis, B. Sibbald, and M. Roland. 2009. "Effects of Pay-for-Performance on the Quality of Primary Care in England." New England Journal of Medicine 361 (4): 368-78.

Casalino, L. P., G. C. Alexander, L. Jin, and R. T. Konetzka. 2007a. "General Internists' Views on Pay-for-Performance and Public Reporting of Quality Scores: A National Survey." Health Affairs (Millwood) 26 (2): 492-99.

Casalino, L. P., A. Elster, A. Eisenberg, E. Lewis, J. Montgomery, and D. Ramos. 2007b. "Will Pay-for-Performance and Quality Reporting Affect Health Care Disparities?" Health Affairs 26 (3): 405-14.
Centers for Medicare \& Medicaid Services (CMS). 2008. "Medicare Physician Group Practice Demonstration: Physicians Groups Continue to Improve Quality and Generate Savings Under Medicare Physician Pay for Performance Demonstration." In Department of Health and Human Services, 8. Baltimore, MD: CMS.

Chen, J. Y., N. Kang, D. T. Juarez, K. A. Hodges, R. S. Chung, and A. P. Legorreta. 2010. "Impact of a Pay-for-Performance Program on Low Performing Physicians." Journal of Healthcare Quality 32 (1): 13-21; quiz 21.

Christianson, J., S. Leatherman, and K. Sutherland. 2008. "Lessons from Evaluations of Purchaser Pay-for-Performance." Medical Care Research and Review 65 (6, Suppl.): 5-35.

Cosier, R. A., and D. R. Dalton. 1988. "Competition and Cooperation: Effects of Value Dissensus and Predisposition to Help." Human Relations 41 (11): 823-39.

Curtin, K., H. Beckman, G. Pankow, Y. Milillo, and R. A. Green. 2006. "Return on Investment in Pay for Performance: A Diabetes Case Study." Journal of Healthcare Management 51 (6): 365-74; discussion 375-76.

Damberg, C., R. Kristiana, S. Teleki, and E. de la Cruz. 2009. "Taking Stock of Pay-forPerformance: A Candid Assessment from the Front Lines." Health Affairs 28 (2): 517-25.

Davis, K. 2008. "Slowing the Growth of Health Care Costs-Learning from International Experience." New England Journal of Medicine 359 (17): 1751-55.

Diamond, F. 2010. "Highmark's P4P Program Uses 2 Different Approaches." Managed Care Magazine. December.

Doran, T., C. Fullwood, and H. Gravelle. 2006. "Pay-for-Performance Programs in Family Practices in the United Kingdom." New England Journal of Medicine 355: 371-84.

Dukerich, J. M., B. R. Golden, and S. M. Shortell. 2002. "Is Beauty in the Eyes of the Beholder? Predicting Organizational Identification and Its Consequences Using Identity and Image." Administrative Science Quarterly 47: 507-33.

Epstein, A. 2007. "Pay for Performance at the Tipping Point." New England Journal of Medicine 356 (5): 515-18.

FitzRoy, F. R., Z. J. Acs, and D. A. Gerlowski. 1998. Management and Economics of Organization. London: Prentice Hall Europe. 
Galvin, R. S., S. Delbanco, A. Milstein, and G. Belden. 2005. "Has the Leapfrog Group Had an Impact on the Health Care Market?" Health Affairs 24 (1): 228-33.

Giraud-Roufast, A., and J. M. Chabot. 2008. "Medical Acceptance of Quality Assurance in Health Care." Journal of the American Medical Association 300 (22): 2663-65.

Glickman, S. W., F. S. Ou, E. R. DeLong, M. T. Roe, B. L. Lytle, J. Muglung, J. S. Rumsfeld, W. B. Gibler, E. M. Ohman, K. A. Schulman, and E. D. Peterson. 2007. "Pay for Performance, Quality of Care, and Outcomes in Acute Myocardial Infarction." Journal of the American Medical Association 297 (21): 2373-80.

Golden, B. R. 2006. "The Cost of Pay-forPerformance in Healthcare; an Alternative View." Healthcare Papers 6 (4): 39-46.

Golden, B. R., and F. A. Sloan. 2008. "Physician Pay for Performance." In Incentives and Choice in Health Care, 289-318. Boston: MIT Press.

Gordon, F. M., K. R. Welch, G. Offringa, and N. Katz. 2000. "The Complexity of Social Outcomes from Cooperative, Competitive, and Individualistic Reward Systems." Social Justice Research 13 (3): 237-69.

Hamblin, R. 2008. "Regulation, Measurements and Incentives. The Experience in the US and UK: Does Context Matter?" Perspectives in Public Health 128 (6): 291-98.

Hare, A. P., H. H. Blumberg, M. F. Davies, and M. V. Kent. 1994. Small Group Research: A Handbook. Norwood, NJ: Ablex.

Hayward, R. A., and D. M. Kent. 2008. "6 EZ Steps to Improving Your Performance (or How to Make P4P Pay 4U!)." Journal of the American Medical Association 300 (3): 255-56.

Himmelberg, C. P., R. G. Hubbard, and D. Palia. 1999. "Understanding the Determinants of Managerial Ownership and the Link Between Ownership and Performance." Journal of Financial Economics 53 (3): 353-84.

Hoff, T., C. W. Hartmann, C. Soerensen, P. Wroe, M. Dutta-Linn, and C. Lee. 2011. "Making the CMS Payment Policy for HealthcareAssociated Infections Work: Organizational Factors That Matter." Journal of Healthcare Management 56 (5): 319-35.

Jauhar, S. 2008. "The Pitfalls of Linking Doctors' Pay to Performance." The New York Times, September 9.
Johnson, D. W., and R. T. Johnson. 1989. Cooperation and Competition: Theory and Research. Edina, MN: Interaction Book Company.

Johnson, R. T., and D. W. Johnson. 1983. "Effects of Cooperative, Competitive, and Individualistic Learning Experiences on Social Development." Exceptional Children 49 (4): 323-29.

Kellis, D. S., and J. S. Rumberger. 2010. "Healthcare Reform and the Hospital Industry: What Can We Expect?" Journal of Healthcare Management 55 (4): 283-96; discussion 296-97.

Kelly, K. 2010. "The Effect of Incentives on Information Exchange and Decision Quality in Groups." Behavioral Research in Accounting 22 (1): 43-65.

Lam, C. K., G. S. van der Vegt, F. Walter, and X. Huang. 2011. "Harming High Performers: A Social Comparison Perspective on Interpersonal Harming in Work Teams." Journal of Applied Psychology 96 (3): 588-601.

Leape, L. L. 1994. "Error in Medicine." Journal of the American Medical Association 272 (23): 1851-57.

Lester, H., J. Schmittdiel, J. Selby, B. Fireman, S. Campbell, J. Lee, A. Whippy, and P. Madvig. 2010. "The Impact of Removing Financial Incentives from Clinical Quality Indicators: Longitudinal Analysis of Four Kaiser Permanente Indicators." British Medical Journal 340: c1898.

Lewin K. 1943. "Defining the 'Field at a Given Time." " Psychological Review 50: 292-310.

Locke, E. A., and G. P. Latham. 1990. A Theory of Goal Setting and Task Performance. Englewood Cliffs, NJ: Prentice-Hall.

Maslow, A. H. 1943. "A Theory of Human Motivation." Psychological Review 50 (4): 370-96.

Mayo. E. 1933. The Human Problems of an Industrial Civilization. Cambridge, MA: Harvard University Press.

McCaul, K. D., B. A. Gladue, and M. Joppa. 1992. "Winning, Losing, Mood, and Testosterone." Hormones \& Behavior 26: 486-504.

McCarney, R., J. Warner, S. Iliffe, R. van Haselen, M. Griffin, and P. Fisher. 2007. "The Hawthorne Effect: A Randomised, Controlled Trial." BMC Medical Research Methodology 7: 30.

McDonald, R., and M. Roland. 2009. "Pay for Performance in Primary Care in England 
and California: Comparison of Unintended Consequences." Annals of Family Medicine 7 (2): 121-27.

Mehrotra, A., M. E. Sorbero, and C. L. Damberg. 2010. "Using the Lessons of Behavioral Economics to Design More Effective Pay-for-Performance Programs." American Journal of Managed Care 16 (7): 497-503.

Meltzer, D. O. 2009. "Social Science Insights into Improving Workforce Effectiveness: Examples from the Developing Field of Hospital Medicine." Journal of Public Health Management and Practice 15 (6, Suppl.): S18-S23.

Meyer, H. 1975. "The Pay-for-Performance Dilemma." Organizational Dynamics 3 (3): 39-50.

Mullen, K. J., R. G. Frank, and M. B. Rosenthal. 2010. "Can You Get What You Pay For? Pay-for-Performance and the Quality of Healthcare Providers." RAND Journal of Economics 41 (1): 64-91.

O’Daly, M., and E. Fantino. 2003. "Delay Reduction Theory." The Behavior Analyst Today 4 (2): 141-55.

Oliver, A., and L. D. Brown. 2011. "Incentivizing Professionals and Patients: A Consideration in the Context of the United Kingdom and the United States." Journal of Health Politics, Policy and Law 36 (1): 59-87.

Pearson, S. D., E. C. Schneider, K. P. Kleinman, K. L. Coltin, and J. A. Singer. 2008. "The Impact of Pay-for-Performance on Health Care Quality in Massachusetts, 20012003." Health Affairs 27 (4): 1167-76.

Pepitone, E. A. 1980. Children in Cooperation and Competition: Toward a Developmental Social Psychology. Lexington, MA: Lexington Books.

Peterson, L. A., L. D. Woodard, T. Urech, C. Daw, and S. Sookanan. 2006. "Does Pay-for-Performance Improve Quality of Health Care?" Annals of Internal Medicine 145 (4): 265-72.

Pfeffer, J., R. B. Cialdini, B. Hanna, and K. Knopoff. 1998. "Faith in Supervision and the Self-Enhancement Bias: Two Psychological Reasons Why Managers Don't Empower Workers." Basic \& Applied Social Psychology 20 (4): 313-21.

Pink, G. H., A. D. Brown, M. L. Studer, K. L. Reiter, and P. Leatt. 2006. "Pay-for-Performance in Publicly Financed Healthcare: Some International Experience and
Consideration for Canada." Healthcare Papers 6 (4): 8-26.

Qin, Z., D. W. Johnson, and R. T. Johnson. 1995. "Cooperative Versus Competitive Efforts and Problem Solving." Review of Educational Research 65 (2): 129-43.

Randolph, D. S. 2005. "Predicting the Effect of Extrinsic and Intrinsic Job Satisfaction Factors on Recruitment and Retention of Rehabilitation Professionals." Journal of Healthcare Management 50 (1): 49-60; discussion 60.

Robbins, P., and T. A. Judge. 2007. Essentials of Organizational Behavior, 9th ed. Upper Saddle River, NJ: Prentice-Hall.

Rosenau, P. 2006. "Is Economic Theory Wrong About Human Nature?" Journal of Economic and Social Policy 10 (2): 61-78.

. 2003. The Competition Paradigm: America's Romance with Conflict, Contest, and Commerce. Lanham, MD: Rowman \& Littlefield.

Ryan, R. M., and E. L. Deci. 2000. "Self-Determination Theory and the Facilitation of Intrinsic Motivation, Social Development, and Well-Being." American Psychology 55 (1): 68-78.

Serumaga, B., D. Ross-Degnan, A. J. Avery, R. A. Elliott, S. R. Majumdar, F. Zhang, and S. B. Soumerai. 2011. "Effect of Pay for Performance on the Management and Outcomes of Hypertension in the United Kingdom: Interrupted Time Series Study." British Medical Journal 342: d108.

Stanne, M. B., D. W. Johnson, and R. T. Johnson. 1999. "Does Competition Enhance or Inhibit Motor Performance: A Metaanalysis." Psychological Bulletin 125 (1): 133-54.

Steinmetz, L. 1983. Nice Guys Finish Last: Management Myths and Reality. Boulder, CO: Horizon.

Strack, F., and R. Deutsch. 2004. "Reflective and Impulsive Determinants of Social Behavior." Personality and Social Psychology Review 8 (1): 220-47.

Thompson, D., R. Socolar, L. Brown, and J. Haggerty. 2002. "Interagency Collaboration in Seven North Carolina Counties." Journal of Public Health Management and Practice 8 (5): 55-64.

Tjosvold, D., and R. Andrews. 1983. "Cooperative and Competitive Relationships Between Leaders and Subordinates." Human Relations 36 (12): 1111-24. 
Vaughan, D. 1999. "The Dark Side of Organizations: Mistake, Misconduct, and Disaster." Annual Review of Sociology 25: 271-305.

Volpp, K. G., D. A. Asch, R. Galvin, and

G. Loewenstein. 2011. "Redesigning Employee Health Incentives-Lessons from Behavioral Economics." New England Journal of Medicine 365 (5): 388-90.

Volpp, K. G., M. V. Pauly, G. Loewenstein, and D. Bangsberg. 2009. "P4P4P: An Agenda for Research on Pay-For-Performance for Patients." Health Affairs 28 (1): 206-14.

Vroom, V. H. (1964). Work and Motivation. New York: Wiley.

Werner, R. M., J. T. Kolstad, E. A. Stuart, and D. Polsky. 2011. "The Effect of Pay-forPerformance in Hospitals: Lessons for Quality Improvement." Health Affairs 30 (4): 690-98.

Wharam, J. F., and D. Sulmasy. 2009. "Improving the Quality of Health Care: Who Is Responsible for What?" Journal of the American Medical Association 301 (2): 215-17.
Wodchis, W. P., J. S. Ross, and A. S. Detsky. 2007. "Is P4P Really FFS?" Journal of the American Medical Association 298 (15): 1797-99.

Workie, A. 1974. "The Relative Productivity of Cooperation and Competition." Journal of Social Psychology 92: 225-30.

Wynia, M. K. 2009. "The Risks of Rewards in Health Care: How Pay-for-Performance Could Threaten, or Bolster, Medical Professionalism." Journal of General Internal Medicine 24 (7): 884-87.

Young, G. J. 2007. "Practical Issues in the Design and Implementation of Pay-forQuality Programs." Journal of Healthcare Management 52 (1): 10-15.

Young, G., M. Meterko, B. White, K. Sautter, B. Bokhour, E. Baker, and J. Silver. 2010. "Pay-for-Performance in Safety Net Settings: Issues, Opportunities, and Challenges for the Future." Journal of Healthcare Management 55 (2): 132-42.

\title{
PRACTITIONER APPLICATION
}

\author{
Caroline R. Piselli, RN, FACHE, clinical \& economic research executive, $3 M$ Health \\ Information Systems, Wallingford, Connecticut
}

T

he authors present a comprehensive evaluation of pay-for-performance (P4P) pro-

grams as they align with issues of effectiveness, social science interrelationships, and budgetary considerations. They provide timely lessons that can be leveraged within today's healthcare transformation to accountable care. I propose that transformation can take place within a pay for outcomes (P4O) framework, which "would adjust payments on the basis of a hospital's relative performance on outcomes rather than processes . . . with initial focus on those outcomes for which a quality failure results in an increase in payment" (Averill, Hughes, and Goldfield 2011). In this model, hospitals are not required to adopt specific care processes to achieve the P4O standards. Their success is predicated on improved quality and access for a defined population of patients and on cost containment as part of an organized team of multiple healthcare providers across the continuum of care (Averill, Hughes, and Goldfield 2011).

\section{POPULATION HEALTH, ANALYTICS, AND OUTCOMES}

Before discussing my view of a $\mathrm{P} 4 \mathrm{O}$ approach to healthcare transformation, I describe the factors that allow $\mathrm{P} 4 \mathrm{O}$ to function in this capacity. 